\title{
Interpretação de representações visuais: Lady Gaga em cena
}

Luciana Coutinho Pagliarini de Souza

Doutora em Comunicação e Semiótica pela Universidade de Sorocaba/Uniso. E-mail: luciana.souza@prof.uniso.br

Maria Ogécia Drigo

Doutora em Comunicação e Semiótica pela Universidade de Sorocaba/Uniso. E-mail: maria.drigo@yahoo.com.br

Resumo: Esse artigo tem como propósito apresentar um instrumental semiótico para orientar a interpretação de representações visuais. Toma-se como objeto de análise uma representação visual da cantora Lady Gaga, valendo-se da semiótica peirciana e do percurso de análise proposto por Santaella. Durand ${ }^{1}$ Miège $^{2}$, Dondis ${ }^{3}$, Santaella e Nöth ${ }^{4}$, além de Maffesoli ${ }^{5}$, são autores que fundamentam aspectos comunicacionais relativos à imagem na contemporaneidade. Constitui a relevância desse artigo enfatizar que o potencial significativo da representação visual está latente na sua própria materialidade.

Palavras-chave: Comunicação, representação visual, interpretação, análise semiótica.
Abstract: This paper aims to present a semiotic instrumental to orient the interpretation of visual representations. A visual representation of Lady Gaga is the object of this analysis, which uses the semiotic of Charles Sanders Peirce and the route of analysis proposed by Santaella. The theoretical foundation about aspects of communication and the image are done with Durand, Miège, Dondis, Santaella and Nöth, and Maffesoli. The relevance of this paper is to emphasize that the significant potential of visual representation is latent in its own materiality.

Keywords: Communication, Visual representation, Interpretation, Semiotic Analysis.

\section{INTRODUÇÃO}

Para Durand ${ }^{6}$, no século XX, os progressos das técnicas de reprodução por imagens, como a fotografia, o vídeo e as imagens sintéticas, bem como os meios de transmissão dessas diversas modalidades, não foram suficientes para a construção de uma "civilização da imagem". O reino da "galáxia de Gutemberg", expressão de McLuhan, foi o da supremacia da imprensa e da comunicação escrita. Ainda segundo Durand ${ }^{7}$, mesmo as sintaxes, as retóricas e os processos de raciocínio envolvendo a imagem mental e a icônica, que permitiram recenseamentos e classificações e tornaram possíveis estudos de processos de produção, transmissão e recepção de imagens, não criaram problemas para tal reinado. Parte dessa produção está minuciosamente analisada em Santaella e Nöth $^{8}$. Esses autores preconizam que uma teoria da imagem ainda está por vir.

Recebido: 24/02/2012

Aprovado: 12/04/2012

1. DURAND, Gilbert. 0 imaginário: ensaio acerca das ciências e da filosofia da imagem. Rio de Janeiro: Difel, 2004.

2. MIÈGE, Bernard. O pensamento comunicacional. Petrópolis: Vozes, 2000.

3. DONDIS, A. Donis. Sintaxe da linguagem visual. São Paulo: Martins Fontes, 2010.

4. SANTAELLA, Lucia; NÖTH, Winfried. Imagem: cognição, semiótica, mídia. São Paulo: lluminuras, 2001.

5. MAFFESOLI, Michel. No fundo das aparências. Petrópolis/RJ: Vozes, 2005.

6. DURAND, op. cit., p. 5.

7. Ibid., p. 5-6.

8. SANTAELLA; NÖTH. Imagem, cit. 
comunicação \& educação • Ano XVII • número 2 • jul/dez 2012

Para Durand, a onipresença da imagem tem um "efeito perverso" que não foi previsto nem considerado. "Embora a pesquisa triunfal decorrente do positivismo tenha se apaixonado pelos meios técnicos (óticos, físico-químicos, eletromagnéticos etc.) da produção, reprodução e transmissão de imagens, ela continuou ignorando o produto de suas descobertas" O Ocidente, que se considera livre da força das imagens devido ao seu "iconoclasmo endêmico", continua relacionando as imagens à distração e menosprezando a sua força.

Todavia, as difusoras de imagens - digamos a "mídia" - encontram-se onipresentes em todos os níveis de representação e da psique do homem ocidental ou ocidentalizado. A imagem mediática está presente desde o berço até o túmulo, ditando as intenções de produtores anônimos ou ocultos: no despertar pedagógico da criança, nas escolhas tipológicas (a aparência) de cada pessoa, até nos usos e costumes públicos ou privados, às vezes como "informação", às vezes velando a ideologia de uma "propaganda", e noutras escondendo-se atrás de uma "publicidade" sedutora" 10 .

Resta acrescentar, no entanto, que nos últimos 25 anos houve significativo interesse pelos estudos da imagem como "fenômeno fundamental da sociedade e pela revolução cultural que implica"11.

Os recursos de comunicação que vêm sendo produzidos e usados com fins pedagógicos, por sua vez, segundo Dondis, não possibilitam a compreensão dos efeitos que as imagens produzem.

$\mathrm{Na}$ verdade, essa é uma esfera em que o sistema educacional se move com lentidão monolítica, persistindo ainda uma ênfase no modo verbal, que exclui o restante da sensibilidade humana, e pouco ou nada se preocupando com o caráter esmagadoramente visual da experiência de aprendizagem (...). Em muitos casos, os alunos são bombardeados com recursos visuais - diapositivos, filmes, slides, projeções audiovisuais -, mas trata-se de apresentações que reforçam sua experiência passiva de consumidores de televisão ${ }^{12}$.

Mas há estudos envolvendo a imagem também na comunicação. Para Miè$\mathrm{ge}^{13}$, o pensamento comunicacional, quando norteado pelo método estrutural e por suas aplicações linguísticas, tomou três direções: da análise estrutural das narrativas, da análise das mensagens visuais e da documentação informatizada.

9. DURAND, op. cit., p. 33.

10. Ibid., p. 34

11. Ibid., p. 34.

12. DONDIS, op. cit., p.17.

13. MIĖGE, B. O pensamento comunicacional. Petrópolis (RJ): Vozes, 2000. p. 34-35.

14. SANTAELLA, Lucia. Semiótica aplicada. São Paulo: Pioneira Thomson Learning, 2002.
$\mathrm{Na}$ primeira prevaleceu o estudo dos textos comunicacionais - discursos da imprensa, mensagens e argumentações publicitárias que levaram ao questionamento da primazia da tradicional análise do conteúdo temático; na segunda, o quadro simplista da comunicação estritamente linguística é superado pelo uso de teorias de Hjelmslev, Greimas, Jakobson e, sobretudo, das de Peirce, cujas propostas são objeto de um interesse crescente entre os especialistas da comunicação.

Barthes e Eco, como exemplos, trataram da análise de mensagens visuais. Entre nós, Santaella ${ }^{14}$ desenvolveu um método de análise para representações visuais a partir da semiótica peirciana. A semiótica fornece um "inventário de tipos de signos e misturas sígnicas, nas inumeráveis gradações entre o verbal 
e o não verbal até o limite do quase-signo. Desse manancial conceitual, podemos extrair estratégias metodológicas para a leitura e análise de processos empíricos de signos"15.

As imagens, por sua vez, para fins de estudo, segundo Santaella e Nöth ${ }^{16}$, podem ser agrupadas em dois domínios: o das imagens na nossa mente e o das imagens enquanto representações visuais. As imagens na nossa mente são vinculadas à imaginação, à fantasia, ao sonho ou a um modelo - e conjugam a impressão dupla de visualização e semelhança. O segundo domínio, que nos importa nessas reflexões, é o das representações visuais, ou dos signos que representam nosso ambiente visual: pinturas, gravuras, desenhos e imagens cinematográficas, televisivas, holográficas ou infográficas. Contudo, esses dois domínios estão interligados - afinal, segundo os mesmos autores, não há como conceber uma imagem representativa desvinculada da imagem mental que a iluminou; da mesma forma, a gênese da imagem mental está na experiência do concreto.

A partir das ideias mencionadas, consideramos que educar o olhar para a "leitura" de representações visuais é necessário. Nesse artigo, apresentamos a análise semiótica da representação visual (Figura 1), com o propósito de enfatizar que o potencial significativo está nela engendrado e pode ser desvelado por meio do exercício de um olhar capaz de contemplar, discriminar e generalizar - olhar esse que corresponde, respectivamente, aos três passos do processo interpretativo: da significação, da referência e da interpretação.

O primeiro olhar, contemplativo, corresponde à face da significação. É o momento em que nos detemos aos aspectos qualitativos vinculados às cores, às formas, às linhas, às texturas, ao movimento, às dimensões ou ao jogo com esses elementos. Aquilo que apela para a nossa sensibilidade são qualidades. Estamos, portanto, numa instância do processo que exige sensorialidade.

O olhar que discrimina - observacional - diz respeito à referência. É a fase da objetivação. Nessa faceta, a análise semiótica nos permite compreender aquilo que as mensagens indicam, aquilo a que se referem ou a que se aplicam. Devem-se desenvolver considerações situacionais sobre o universo no qual o signo se manifesta e do qual é parte - observando, ainda, aquilo que faz dele irrepetível e único em contextos socioculturais que estão fora dele, mas que o determinam.

Por fim, o terceiro olhar, generalizante, leva-nos ao exame dos efeitos que os elementos apreendidos até então podem provocar no intérprete e o sintetizar intelectualmente. Entram aqui os conhecimentos do leitor sobre cada elemento da imagem que lê - conhecimento este que permitirá a articulação das qualidades atualizadas existentes no processo que caracteriza a ação do signo produzindo signos: a semiose.

Para o exercício desses modos de olhar, apresentamos, a seguir, a análise semiótica da representação visual de Lady Gaga (Figura 1).
15. Ibid., p. XIV.

16. SANTAELLA, Lucia; NÖTH, Winfried. Imagem, cit., p. 15. 
comunicação \& educação • Ano XVII • número 2 • jul/dez 2012

\section{O POTENCIAL SIGNIFICATIVO DE UMA REPRESENTAÇÃO VISUAL DE LADY GAGA}

Iniciemos com os aspectos qualitativos que vêm das cores, formas, linhas e movimentos, ou com jogos desses aspectos. As cores predominantes na imagem são o vermelho (num tom brilhante e denso) e os tons amarelados (brilhantes, claros, fulgurantes). Linhas sinuosas se misturam a linhas retas e pontiagudas. Há, ainda, linhas arredondadas desenhadas pela posição dos braços e das pernas. A textura é levemente rugosa.

$\mathrm{O}$ vermelho sugere força e vivacidade, enquanto o amarelo - translúcido e reluzente - sugere divindade, poder. A forma, que advém dos jogos com as linhas sinuosas e com os gestos, sugere leveza, ato de entrega, transcendência. A textura convida à surpresa, um caminho que vai do liso ao levemente áspero.

Essas sensações emergem porque o ato perceptivo está impregnado de elementos gerais referentes, também, às cores, às formas e às texturas. Entre esses elementos, o "vermelho claro, brilhante, centrífugo, é diurno, macho, tônico, incitando à ação, lançando, como um sol, seu brilho sobre todas as coisas, com uma força irredutível"17. Ele pode provocar certa inquietude, agitação. Já os tons amarelados - presentes, por sua vez, por ser o amarelo a cor da eternidade, como o ouro é o metal da eternidade - podem provocar uma reação de admiração à imagem de Lady Gaga, no caso, um pouco desmedida, quase de veneração, aproximando-se do que uma imagem sagrada suscita. Já a textura que vem com o véu (tecido rendado que reveste o corpo como uma pele) propicia certa ansiedade e, talvez, provoque o desejo de "espiar", devido ao jogo que oculta e, ao mesmo tempo, revela o corpo.

17. CHEVALIER, Jean; GHEERBRANT, Alain. Dicionário de símbolos: mitos, sonhos, costumes, gestos, formas, figuras, cores, números. Rio de Janeiro: J. Olympio, 2007. p. 944.

18. Disponível em: <http:// images2.fanpop.com/ image/photos/8500000/ Lady-GaGa-Runway-After-Party-lady-gaga-8589217-532-800.jpg>. Acesso em: 12 ago. 2010.

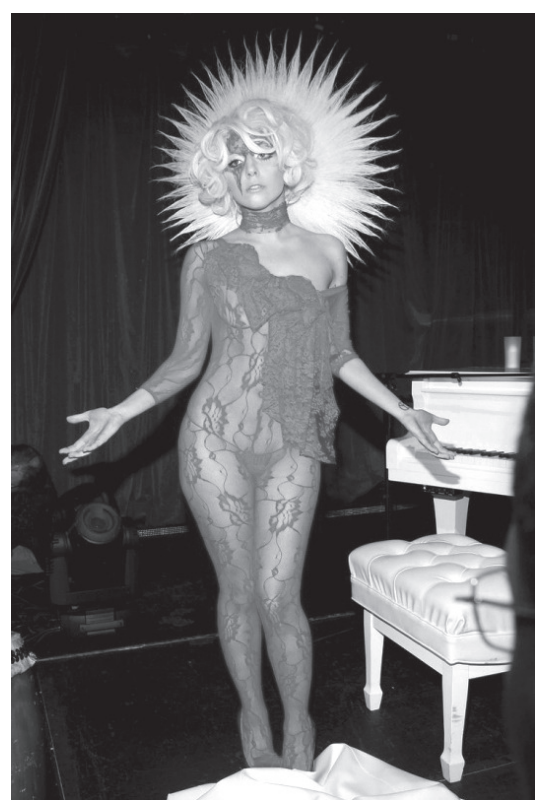

Lady Gaga: o sagrado e o profano em cena ${ }^{18}$. 
Dando vazão ao olhar observacional, apreendemos os aspectos referenciais da imagem. Trata-se da foto de uma mulher jovem, com um traje rendado num tom vermelho vibrante, que deixa o corpo como que coberto por um véu. As curvas do decote exibem seu colo, enquanto uma faixa ao redor do pescoço, como um colar, deixa-o mais fino e alongado, impondo uma distância maior entre a cabeça e o restante do corpo. Os cabelos amarelados - em um tom amarelo translúcido - são ondulados e firmes. Há ao redor da cabeça um tipo de auréola dourada, similar à parte superior de um ostensório. A maquiagem ganha, como acabamento, um aplique em renda em torno de um dos olhos e na parte superior do rosto; os olhos são também realçados pela cor branca abaixo das sobrancelhas. Há ainda uma tatuagem no braço, bem próxima a uma das mãos.

Lady Gaga, cantora pop de destaque na mídia, da impressa à internet, é a mulher fotografada. Os delírios estéticos da cantora organizam novas "tribos" no sentido proposto por Maffesoli. Nesse caso, trata-se de uma espécie de "religião" baseada na música dance "grudenta" e nas roupas ousadas: o "gagaísmo". Suas seguidoras usam lingeries à mostra, meias rendadas, hotpants, acessórios extravagantes e looks fantasia. Para selecionar peças na composição de um look em sintonia com o da artista, podem-se seguir algumas regras e atitudes organizadas em dez mandamentos que, segundo Whiteman ${ }^{19}$, são os seguintes: 1. Sinta-se livre para ser freak e desavergonhada; 2. Esteja sempre fabulosa e considere que "trocar de roupa" é uma diversão; 3. Guie-se pelo sagrado triângulo do estilo: moda, música pop e arte; 4. Aprecie os clássicos do passado, mas sempre aumente mil graus na ousadia; 5. Siga os mestres da imagem: inspire-se nos grandes fotógrafos de moda; 6. Pratique o dadaísmo fashion - não importa se não faz sentido, é divertido usar um telefone na cabeça ou um chapéu de lagosta durante o jantar; 7. Projete mensagens visuais impactantes através de suas roupas; 8 . Sustente o seu look, porque o show tem que continuar; 9. Os "monstrinhos" de hoje serão os reis e rainhas do estilo amanhã, e 10. Não se contente com a cópia: escreva sua própria história. Assim, podemos dizer que há um culto à aparência que enfatiza o que está distante de padrões estabelecidos pela moda.

Nesse momento, o terceiro modo de olhar - o interpretativo - tem lugar. O "gagaísmo fashion", denominando essa nova maneira de construir a aparência - ou o look -, remete-nos ao movimento da chamada vanguarda artística, o dadaísmo. Segundo Wood $^{20}$, tal movimento voltava-se a uma crítica à obra de arte esteticamente autônoma e à forma de vida que a sustentava. Dessa forma, sua característica principal foi a ruptura com as formas de arte tradicionais, sendo, portanto, um movimento de forte conteúdo anárquico. Os artistas dessa tendência se valeram de várias formas de expressão, baseadas em objetos do cotidiano, sons, fotografias, poesias, músicas e jornais, entre outros - selecionando temas e conteúdos absurdos, aparentemente sem lógica, em obras muitas vezes impregnadas de ironia. Marcel Duchamp, Francis Picabia e Max Ernst são representantes dessa tendência.
19. WHITEMAN, Vivian. Estilista de Lady Gaga decifra razões da fama e do culto visual à cantora. Folha de S. Paulo, 26 mar. 2010. Disponível em: <http://www1.folha. uol.com.br/folha/ilustrada/ult90u712289.shtml>. Acesso em: 3 maio 2012. 20. WOOD, Paul. Arte conceitual. São Paulo: Cosac \& Naif, 2002. p. 14. 
comunicação \& educação • Ano XVII • número 2 • jul/dez 2012

Ao observarmos os mandamentos do "gagaísmo", podemos constatar uma aproximação não apenas nominal ao dadaísmo - uma vez que ambos tratam da construção da aparência, de um look que, mesmo quando se reportar ao já instituído, deve ousar, ir além, sem deixar de apelar para algo que pareça "sem sentido". Há, portanto, exagero tanto na construção como na preocupação com a construção da aparência. "A imagem de Gaga, de certa forma, corresponde ao sonho dourado da indústria fashion: é a mulher disposta a usar qualquer loucura criada pelos grandes estilistas"21.

Os mandamentos organizam uma maneira irônica de lidar com valores do contemporâneo, que, segundo Maffesoli, se constitui no "reino das aparências" - aparências essas que não são ocas, mas latentes de significados. $\mathrm{O}$ pós-modernismo, para esse sociólogo, caracteriza-se por retomar uma participação mágica das pessoas no meio social, envolvendo três aspectos: o tribalismo - viver com o outro; a magia - viver com o mundo; e a ecologia - viver com a natureza. Desse modo, não há lugar para uma identidade sexual, ideológica ou profissional, mas para a "perda de si, do dispêndio e outros processos que ressaltam a abertura, o dinamismo, a alteridade, a sede do infinito" ${ }^{22}$. O tribalismo caracteriza-se como o fenômeno cultural que envolve o "cotidiano e seus rituais, as emoções e as paixões coletivas, simbolizadas pelo hedonismo de Dionísio, a importância do corpo em espetáculo e do gozo contemplativo, a revivescência do nomadismo contemporâneo" ${ }^{23}$.

Nesse sentido, o conceito também se aproxima do dadaísmo nas artes plásticas. Trata-se de uma imagem contemporânea que brinca, num jogo irônico, com aspectos da contemporaneidade. Estes são os aspectos de caráter geral.

O efeito, porém, pode ser também o de simples constatação: "É a Lady Gaga em mais um de seus trajes polêmicos!", poderá dizer o intérprete. Porém há, na aparência e materialidade da representação visual, pistas que nos levam a outros contextos - e que podem ser perseguidas caso o intérprete possua um repertório, uma experiência colateral que o capacite para tal tarefa. Iniciemos pelos cabelos à moda Marylin Monroe, que trazem à imagem de Lady Gaga todo um conjunto de significados já construídos em torno da figura "hollywoodiana", um dia expressa nas conhecidas telas de Andy Warhol - e que, por sua vez, nos lembra ainda a cantora Madonna, que também se valeu de imagens dessa atriz.

Sem nos prendermos a uma ou outra pista, a imagem, na sua totalidade, nos remete ao século XII e à mística vinculada às filosofias da natureza (Figura 2), lembrando as efígies sagradas do cristianismo e de diferentes seitas.

21. WHITEMAN, op. cit.

22. MAFFESOLI, Michel. O tempo das tribos: 0 declínio do individualismo nas sociedades de massa. Rio de Janeiro: Forense Universitária, 2006. p. 16.

23. Ibid., p. 3.

24. CHEVALIER; GHEERBRANT, op. cit.
Essas representações permeiam as mais diversas mídias e, de certo modo, dialogam com nosso imaginário, nos levando a ler a imagem de Lady Gaga de um modo peculiar. As pistas mencionadas, por sua vez, incitam nossa mente, insistem e, nesse movimento, possibilitam associações a diferentes convenções e aspectos culturalmente compartilhados. Seguem alguns deles.

A Figura 2, por um lado, faz referência aos quatro elementos e, portanto, nos remete à filosofia da natureza - incorporada a diversas seitas que contam com seguidores até os dias atuais, como a Cabala, a Rosa-Cruz e a Maçonaria. 


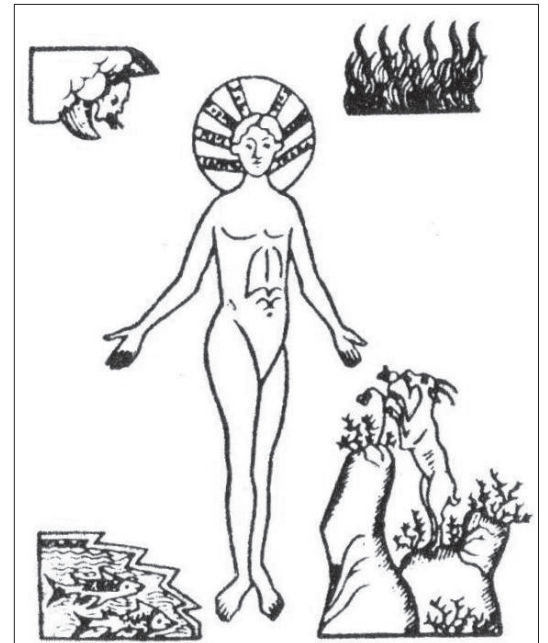

Elementos: miniatura do século XII. Arte alsaciana $^{24}$.

A imagem de Lady Gaga, por sua vez, pode resgatar os aspectos simbólicos que caracterizam tais seitas.

Por outro lado, a imagem também nos remete ao cristianismo, fazendo referência ao corpo em ato de entrega que perde o peso da matéria e do mundano, conquistando a leveza, o fluido, o espiritual. É um corpo em ascensão, tal como a elevação de Jesus ao céu quarenta dias depois de ressuscitado (Figura 3).

A foto de Lady Gaga mostra um tecido branco acetinado aos pés da cantora, lembrando um manto ou vestes que rolaram pelo corpo, deixando-o desnudo. O sagrado e o profano, portanto, estabelecem diálogo nessa imagem, tanto pela apropriação já mencionada como pelo corpo que se apresenta revestido por um véu vermelho. A palavra "véu" está vinculada à árabe hijab, que quer dizer "o que separa duas coisas".

Então véu significa - dependendo se é usado ou retirado - o conhecimento oculto ou revelado. Assim, na tradição cristã monástica, tomar o véu significa separar-se do mundo, mas também separar o mundo da intimidade na qual entramos numa vida com Deus ${ }^{25}$.

Desse modo, há um corpo que se entrega ao observador, ao mesmo tempo que se retira, jogo propiciado pelo vermelho que se lança ao olhar de quem o vê com a mesma força dos raios de luz, enquanto o véu esconde esse corpo.

A tatuagem no braço da cantora (Figura 4), por sua vez, remete-nos ao símbolo dos hippies que, na década de 1960, criaram novos modos de vestir e de falar, defendendo ideias distintas das convencionais na época. Influenciando vários movimentos, eram pacifistas, tendo realizado vários protestos contra a Guerra do Vietnã - bem como condenando o capitalismo e o socialismo. Roupas descontraídas,

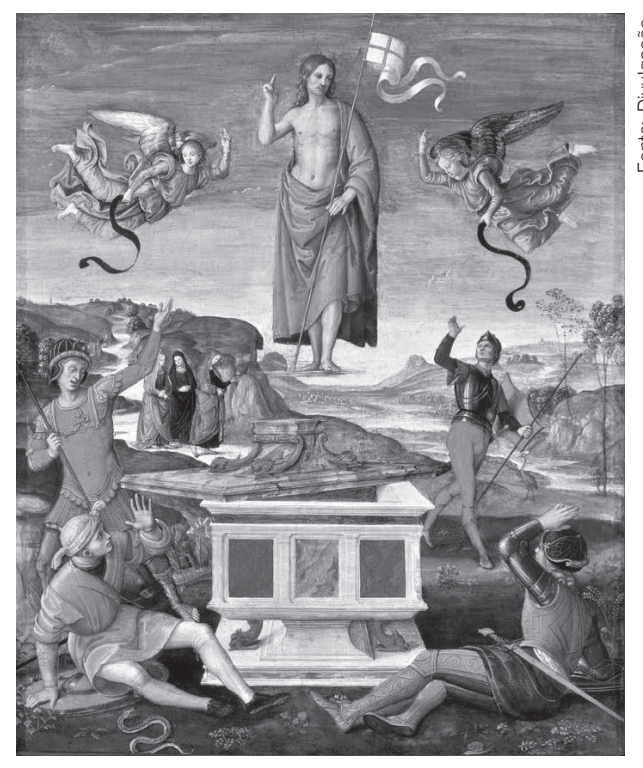

A ressurreição de Cristo, de Raffaello Sanzio. Óleo sobre madeira/1499-1502/52 x 44 cm, Museu de Arte de São Paulo. 


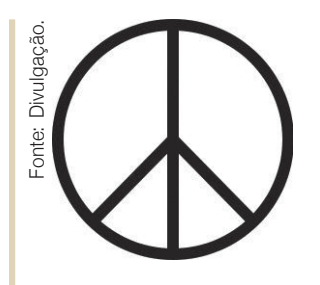

Símbolo do movimento hippie. calças boca de sino e cabelos fartos - além da opção por Jimi Hendrix no toca-fitas, pelo pacifismo e pelo respeito à natureza - eram algumas das características dos simpatizantes da teoria "Paz e Amor".

Com base nessa análise, percebemos que a imagem de Lady Gaga apresenta um conjunto de aspectos indiciais e pistas que nos remetem a outros contextos - ao mundo de Hollywood, ao universo da contestação pacífica dos hippies, às referências do sagrado e do profano e ao universo da arte. Por essas razões, é possível caracterizá-la como contemporânea, à medida que estabelece diálogos com outras "tribos", resgatando o arcaico e o primitivo num jogo sensual, dionisíaco. Da mesma forma, pode ser associada a imagens que vêm de outras mídias. Ao incorporar elementos dessas imagens, ela se mostra volátil e capaz de envolver aspectos do sagrado e do profano, do mítico e do midiático. Dessa forma, flui no tempo e permanece, ao se metamorfosear incessantemente - reunindo tribos, aproximando as pessoas e propiciando o "estar junto" -, reportando-nos, portanto, às ideias de Maffesoli.

Ao realizarmos uma análise semiótica, explicitamos possíveis significados que uma interpretação particular pode apreender, já que, por vezes, não se pode identificar todo o potencial significativo dessa ou de qualquer outra representação visual. No entanto, os significados estão expressos, latentes na tessitura constituída pela materialidade da representação visual.

\section{CONSIDERAÇÕES FINAIS}

É pertinente a ênfase dada por Maffesoli ao aprendizado de olhar para a materialidade da imagem ou para o "fundo das aparências". Compreender as relações sociais desenhadas no cotidiano envolve educar o olhar para as imagens que tomam forma nessas relações e que, por sua vez, abarcam também as imagens disseminadas pelas mídias.

As imagens permeiam todas as relações sociais no contemporâneo, quer seja por se apresentarem, por se deixarem ver - caso das representações visuais de modo geral -, quer seja por se incorporarem, em algum aspecto, ao imaginário das pessoas. Mesmo quando estáticas, as imagens possuem um dinamismo próprio que fortalece os sentimentos experimentados em comum.

A imagem vivida no cotidiano, a imagem banal das lembranças, a imagem dos rituais diários, imobiliza o tempo que passa. Seja a da publicidade, a da teatralidade urbana, a da televisão onipresente ou dos objetos a consumir, sempre insignificante ou frívola, ela não deixa de delimitar um ambiente que delimita bem a sequência de passagens em momentos, lugares, encontros justapostos ${ }^{26}$.

Neste caso, a foto de Lady Gaga, pelas cores e texturas de suas roupas, pelas formas arredondadas do corpo sob o véu ou pelos vínculos simbólicos que ela guarda, constitui uma imagem capaz de juntar as pessoas, ou seja, mostra um dinamismo próprio que fortalece os sentimentos experimentados em comum. 
Interpretação de representações visuais - Luciana C. P. de Souza e Maria O. Drigo

O método de análise utilizado permite resgatar todos os aspectos mencionados e que estão na "imagem", na aparência, na epiderme, na superfície. O olhar pertinente, portanto, permite elaborar um inventário do potencial significativo de representações visuais que torna claro esse potencial e que permite, de certo modo, desmistificar os possíveis poderes perversos dessas representações. Esses poderes são amenizados à medida que o intérprete "educa o olhar" para adentrar todas as fendas que os aspectos qualitativos, referenciais e simbólicos deixam expostas.

\section{REFERÊNCIAS BIBLIOGRÁFICAS}

CHEVALIER, Jean; GHEERBRANT, Alain. Dicionário de símbolos: mitos, sonhos, costumes, gestos, formas, figuras, cores, números. Rio de Janeiro: José Olympio, 2008.

DONDIS, A. Donis. Sintaxe da linguagem visual. São Paulo: Martins Fontes, 2010. DURAND, Gilbert. O imaginário: ensaio acerca das ciências e da filosofia da imagem. Rio de Janeiro: Difel, 2004.

MAFFESOLI, Michel. No fundo das aparências. Petrópolis/RJ: Vozes, 2005.

O tempo das tribos: o declínio do individualismo nas sociedades de massa. Rio de Janeiro: Forense Universitária, 2006.

SANTAELLA, Lucia. Semiótica aplicada. São Paulo: Pioneira Thomson Learning, 2002.

; NÖTH, Winfried. Imagem: cognição, semiótica, mídia. São Paulo: Iluminuras, 2001.

WHITEMAN, Vivian. Folha de S. Paulo. E4 Ilustrada. 26 mar. 2010.

WOOD, Paul. Arte conceitual. São Paulo: Cosac \& Naif, 2002.

\section{Endereço eletrônico}

WHITEMAN, Vivian. Estilista de Lady Gaga decifra razões da fama e do culto visual à cantora. Folha de S. Paulo, 26 abr. 2010. Disponível em: <http:/ /www1. folha.uol.com.br/folha/ilustrada/ult90u712289.shtml>. Acesso em: 3 maio 2012. 


\section{Assine a revista Comunicação \& Educação}

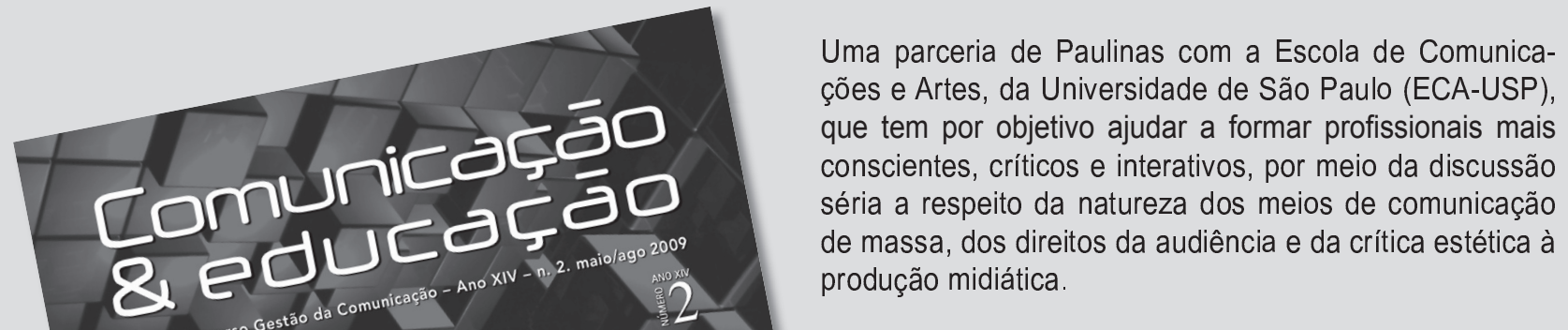

Revista Comunicação \& Educação

Periodicidade: semestral
Ensaios, entrevistas e debates com os maiores especialistas da área auxiliam educadores a incluir em suas práticas novas linguagens e novos recursos pedagógicos.

\section{ADQUIRA TAMBÉM OS EXEMPLARES AVULSOS!}
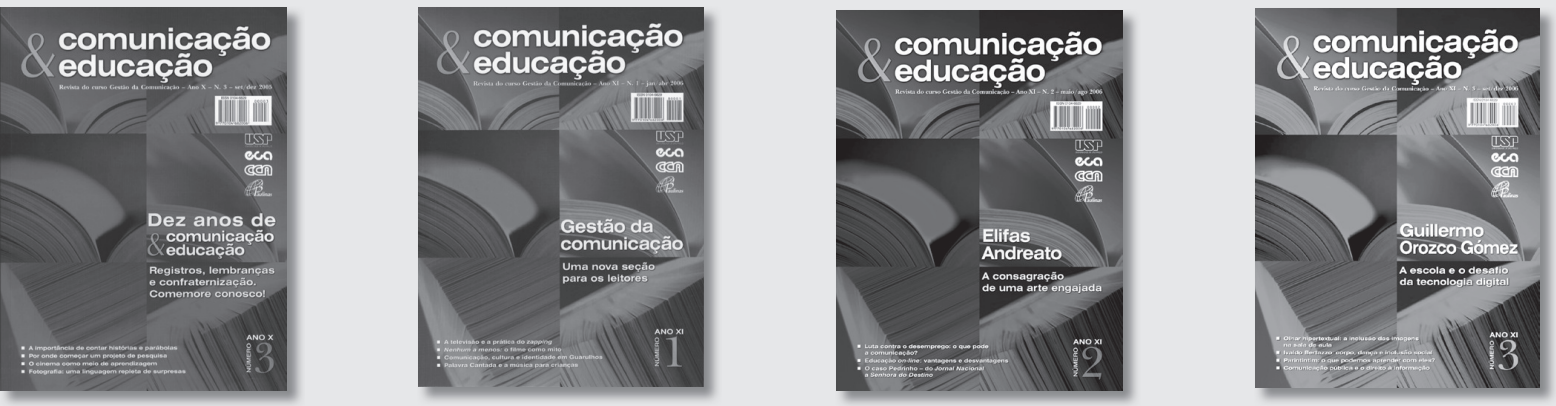

\section{VOCÉ ESCOLHE COMO QUER PAGAR!}

- Cartão de crédito - Visa, Mastercard ou Dinners • Boleto bancário

- Depósito bancário identificado • DOC ou transferência bancária

Ligue 0800-7010081 ramal 9448 ou assine

pela livraria virtual Paulinas, acessando www.paulinas.org.br

Informações: livirtual@paulinas.com.br

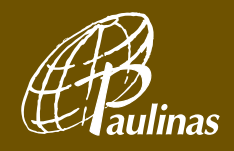

